TRANS · núm. 25·2021

DOSIER $\cdot 89-106$

En esta contribución presentamos un panorama de las traducciones realizadas entre lenguas peninsulares en el siglo XVI. Tomamos el catalán y el portugués como lenguas de partida y el castellano como lengua de llegada, además de las combinaciones que puedan establecerse entre ellas. Para contextualizar nuestro objeto de estudio, dedicamos un apartado a las «traducciones intrapeninsulares» en la Edad Media, que completamos con lo ocurrido en la transición de los siglos XV a XVI, para finalmente detenernos en las traducciones entre lenguas peninsulares en el siglo XVI, un siglo en que el castellano ocupa el centro del polisistema peninsular.

PALABRAS CLAVE: historia de la traducción, traducciones intrapeninsulares, catalán, portugués, castellano, siglo XVI.

\title{
Traducciones entre lenguas peninsulares en el siglo XVI
}

\author{
José Antonio Sabio Pinilla \\ Universidad de Granada
}

\section{Translations Between Peninsular Languages in the $16^{\text {th }}$ Century}

In this paper we present an overview of the translations carried out between peninsular languages in the $16^{\text {th }}$ century. We focus on Catalan and Portuguese as the source languages and Castilian Spanish as the target language, as well as any combinations between these. In order to provide a context for our study, one section is devoted to "intra-peninsular translations" in the Middle Ages, which we complete by addressing what occurred during the transition between the $15^{\text {th }}$ and $16^{\text {th }}$ centuries. Finally, we study translations between peninsular languages in the $16^{\text {th }}$ century, when Castilian Spanish occupied the central position in the peninsular polysystem.

KEY WORDS: history of translation, intra-peninsular translations, Catalan, Portuguese, Castilian Spanish, $16^{\text {th }}$ century. 


\section{INTRODUCCIÓN}

En esta contribución presentamos un panorama de las traducciones realizadas entre lenguas peninsulares en el siglo XVI. Tomamos el catalán y el portugués como lenguas de partida y el castellano como lengua de llegada, además de las combinaciones que puedan establecerse entre ellas. Hasta entrar en el período de los «Séculos escuros» (Noia, 2004: 744), el gallego medieval fue la lengua poética de las Cantigas de Santa María y de los Cancioneiros galaico-portugueses y tuvo traducciones de obras históricas y jurídicas desde el siglo XIII; sin embargo, no incluimos en este trabajo el gallego porque desde el siglo XVI hasta el siglo XIX dejó de ser lengua literaria para recluirse en el ámbito familiar y coloquial, como tampoco incluimos el vasco, pues su actividad traductora arranca en 1571 con el Nuevo Testamento de Joanes Leizarraga (Mendiguren, 2004: 791). Para contextualizar nuestro objeto de estudio, dedicamos un apartado a las «traducciones intrapeninsulares» (Russell, 1985: 9) en la Edad Media, que completamos con lo ocurrido en la transición de los siglos XV a XVI, para detenernos finalmente en las traducciones entre lenguas peninsulares en el siglo XVI, un siglo en que el castellano ocupa el centro del polisistema peninsular.

Antes de iniciar nuestro recorrido, conviene hacer algunas precisiones metodológicas. Usamos el sustantivo «traducciones» en sentido genérico con el objetivo de ofrecer una muestra amplia y a la vez representativa de las obras traducidas entre las diferentes lenguas peninsulares en el siglo XVI. De este modo, el lector podrá encontrar a lo largo del presente trabajo referencias a traducciones de obras de carácter espiritual, doctrinal, histórico, geográfico y científico, sobre todo en relación con los descubrimientos y las empresas ultramarinas, además de traduc- ciones de obras literarias en prosa y en verso. En este repaso, en el que hemos optado por el orden cronológico, le dedicamos un apartado especial a las traducciones de Os Lusíadas por considerarlas la manifestación más importante de la historia de las traducciones intrapeninsulares del siglo XVI, sin descartar el valor de las traducciones de la poesía de Ausiàs March.

En cuanto al marco teórico, de acuerdo con los postulados de Itamar Even-Zohar, entendemos el espacio peninsular como un polisistema cultural heterogéneo compuesto por varios sistemas que se entrecruzan y se superponen parcialmente. En el polisistema peninsular del siglo XVI confluyen en un ambiente multilingüe tres sistemas culturales, castellano, catalán y portugués, que se encuentran en tensión dinámica con tendencia a un movimiento centrípeto, en la medida en que el castellano se convierte progresivamente en el sistema hegemónico. Este proceso se da con distintos niveles de intensidad e influencia mutua y condiciona la producción de traducciones a las otras lenguas, que adquieren una posición periférica con el avanzar del siglo. La práctica de la traducción surge así como un tipo de transferencia que, además de favorecer la interferencia, revela las tensiones existentes entre los diferentes sistemas culturales de la Península. Esta situación es bien patente en el sistema literario portugués debido al bilingüismo imperante en Portugal desde mediados del siglo Xv y cuyas consecuencias más visibles fueron el uso del castellano tanto en las creaciones originales de los escritores lusos como en las traducciones que realizaron, la autotraducción y la escasez de traducciones en portugués no solo de obras en castellano, sino también de otras lenguas. Algo similar sucede en el sistema catalán que pasará a ocupar una posición periférica en el siglo Xvi después de haber ocupado una posición central en el polisis- 
tema peninsular medieval. Resulta sintomático de la situación descrita que las traducciones de obras en castellano desaparezcan del sistema catalán durante el siglo XVI y que en Portugal se publiquen tantas obras en castellano como traducciones al portugués de otras lenguas y que de estas solo seis sean del castellano. Todo ello conduce a la siguiente paradoja: si, por un lado, las obras originales en castellano ocupan una posición central en el polisistema cultural de la Península, por otro, las obras castellanas traducidas a las demás lenguas peninsulares asumen una posición extremadamente periférica.

\section{LAS «TRADUCCIONES INTRAPENINSULA- RES» DURANTE LA EDAD MEDIA}

La traducción entre lenguas peninsulares es un fenómeno documentado desde el siglo XIII, aunque no se generalizará hasta el siglo XIV. Además del aragonés, castellano, catalán y gallego-portugués ${ }^{1}$, en este siglo comienza a traducirse de otros idiomas como el griego, francés, italiano y provenzal, y el latín sustituye progresivamente al árabe como lengua de partida. Entre los aspectos definidores señalados por Santoyo (1994: 31-32; 2009: 302-303), cabe resaltar el papel precursor que tuvo la traducción en Cataluña, que hizo de puente cultural en la Península.

El gallego-portugués es la denominación genérica para el gallego medieval y el portugués antiguo desde el siglo XII hasta mediados del siglo XIV cuando gallego y portugués se consolidan como lenguas diferentes. El gallego, relegado a un uso coloquial a partir del siglo XVI, volverá a usarse literariamente en el XIX con el Rexurdimento y obtendrá estatuto de lengua cooficial en 1936, pero, debido a la guerra civil y posterior dictadura franquista, no será hasta la Constitución de 1978 cuando se consolide como tal y alcance su estandarización. El portugués, impulsado por la independencia de Portugal en el siglo XII y el desplazamiento de la corte a Lisboa a mediados del siglo XIII, alcanza rango de lengua oficial en 1290 durante el reinado de Dionisio I (D. Dinis).
En el siglo XIV se traduce más del latín al ca91 talán que del latín al castellano y las traducciones catalanas sirven de versiones intermedias a traducciones castellanas como, por ejemplo, el Llibre anomenat de Valeri Màxim dels dits \& fets memorables (h. 1395) de Valerio Máximo, traducido por fray Antoni Canals, del que se hicieron al menos tres traducciones al castellano en el siglo XV (Santoyo, 1994: 21; 2009: 255); o la Consolació de la Filosofia de Boecio, obra de los frailes dominicos Pere Saplana, que la tradujo entre 1358 y 1362 , y Antoni Ginebreda, que la revisó y añadió un prólogo propio y comentarios hacia 1390 (Pujol, 2004: 638-639), y de la que deriva la traducción castellana que tuvo tres impresiones a finales del siglo XV (Santoyo, 2009: 257-258). En la dirección catalán-castellano destaca la traducción del Llibre del gentil e dels tres savis (h. 1274-1276) de Ramón LIuII, en versión del cordobés Gonzalo Sánchez de Uceda, Libro del gentil y de los tres sabios, concluida en 1378 (Santoyo, 1994: 27).

Asimismo, en este siglo se inaugura la reflexión traductora, sobre todo en catalán: traductores como Guillem Corretger, Antoni Canals, Ferrer Sayol, Guillem Nicolau, Jaume Conesa, Bernat Metge o Arnau Estanyol, ligados en su mayoría a la Corte de Aragón, reflexionaron sobre las dificultades de traducir obras clásicas y medievales. El aragonés conoce en esta centuria su época dorada como lengua meta, gracias al mecenazgo de Juan Fernández Heredia, con traducciones del francés, griego, latín e italiano, sirviendo en ocasiones el catalán de lengua intermedia (Santoyo, 1994: 25-26; 2009: 276-282).

Las traducciones entre castellano y portugués se documentan en menor medida: del castellano se tradujeron las Vidas e paixões dos apóstolos de Bernardo de Brihuega y el Pobre livro de confissões (1399) (Santoyo, 2009: 289). Por su parte, los relatos del ciclo bretón proceden en castellano de versiones portuguesas de textos france- 
92 ses; de este tipo de literatura artúrica pueden citarse el Libro de Josep de Arimatea, que derivaría de uno anterior en gallego-portugués (Santoyo, 2009: 293), y la Demanda do Santo Graal, que introduce este tema en Portugal y fue modelo de la versión castellana de 1515, aunque a ambas versiones se les supone un antepasado común en lengua peninsular.

También hubo traducciones del castellano al gallego: treinta y seis estrofas del Libro del Buen Amor, del Arcipreste de Hita, traducidas en la segunda mitad del siglo xiv; dos traducciones de la Historia Troiana, que derivan de una versión previa castellana; las traducciones de la Crónica General, de la Crónica de Castilla y de la Crónica de San Fernando, hechas muy a principios de siglo, durante el reinado de Fernando IV (1295-1312) y que constituyen la Crónica Gallega (Santoyo, 1994: 26-27; 2009: 283-284).

El siglo Xv es un siglo abundante en traducciones, pues la mayoría de los escritores son traductores: Juan de Mena, Alonso de Madrigal, el Tostado, Enrique de Villena, Juan Rodríguez del Padrón, Juan del Enzina, Alfonso de Cartagena, Antonio de Nebrija o Alfonso de Palencia son algunos nombres del ámbito castellano, como Andreu Febrer, Ferran Valentí o Francesc Alegre lo son del catalán. En Portugal, se inicia en este siglo la traducción en prosa de textos latinos clásicos y medievales bajo el patrocinio de la Casa de Avís. El desarrollo de esta actividad contó con la colaboración de humanistas como Alfonso de Cartagena. En una de sus misiones a Portugal (1421-1423), el futuro rey don Duarte (1391-1438) le solicitó que tradujera al castellano el De inventione de Cicerón y, muy probablemente, conversaron sobre la mejor manera de traducir del latín al vulgar; esas conversaciones en forma de consejos se recogen en el capítulo 99 del Leal Conselheiro, obra de carácter misceláneo compuesta por don Duarte antes de su muerte. Durante la regencia (1439-1448) del infante don Pedro, el cordobés Vasco Fernandes de Lucena tradujo al portugués, por encargo suyo, el De senectute de Cicerón. Antes de 1454 encontramos la primera obra inglesa traducida en castellano, la Confysion del amante de John Gower, elaborada por Juan de Cuenca a partir de la versión portuguesa de Robert Payn (Santoyo, 2009: 339).

El Condestable don Pedro de Portugal, hijo del infante don Pedro, fue el primer portugués en usar literariamente el castellano, lengua a la que autotradujo en torno a 1447 la Sátira de infelice e felice vida (Santoyo, 2009: 338). Otros autores que recurrieron a la autotraducción en el siglo $\mathrm{xv}$ fueron Enrique de Villena, que escribió en catalán y luego tradujo al castellano Los doce trabajos de Hércules (1417), y Bernardí de Vallmanya, que traduce Revelació de Sanct Pau en valenciana prosa y vierte después al castellano (Camps i Perarnau, 2008: 363).

Entre los datos que ofrece Faulhaber (1995, apud Camps i Perarnau, 2008: 367-368) en su análisis de la traducción en la Edad Media, destacan los siguientes: se documentan treinta y nueve traducciones del catalán al castellano y diez del castellano al catalán, diferencia que refleja la posición central del catalán en el polisistema peninsular medieval y que se mantendrá hasta principios del siglo Xvi; ambas lenguas usan de modo parecido la traducción indirecta: el castellano usa el catalán para traducir textos latinos y el latín para traducir textos griegos, mientras que el catalán usa el latín para traducir del griego y del árabe y las lenguas romances — castellano, francés, italiano y provenzalpara traducir del latín; hay más coincidencias entre las traducciones de castellano y catalán que entre las de castellano y portugués y muchas más que entre las de catalán y portugués. 
Consecuencia de la mayor actividad traductora desarrollada en catalán y en castellano durante la época medieval es la aparición en el siglo XV de los verbos traduir y traducir, con sus derivados: las primeras menciones de traducir y de traducción se atestiguan hacia 1438 en el proemio-dedicatoria a Juan II de La yliada de homero en romãce; traductor se documenta hacia 1520 en el prólogo de la traducción anónima de la Divina Comedia; traduir aparece en 1472 en el colofón de la traducción que hizo Francesc Alegre de las Guerres Púniques; dos años después, en 1494, se documentan tradució y traduidor en otra versión de Francesc Alegre: Transformacions o Metamorfosis de Ovidio. En portugués, traduzir no se data en su forma de participio hasta 1537 en el colofón del Arte para bem confessar; tradução se registra a mediados del siglo XVI en el título de un soneto de André Falcão de Resende y tradutor no lo hace hasta 1682 en el Prólogo ao Leitor del Godofredo, ou Jerusalém Libertada de André Rodrigues de Matos (Sabio Pinilla, 2012).

\subsection{La transición del siglo XV al XVI}

El paso del siglo XV al XVI comporta un dominio progresivo del castellano en el mapa lingüístico peninsular que relega a una posición cada vez más secundaria al catalán. Algunos factores que explican este predominio son la ausencia de una corte real en tierras de habla catalana, la reforma de las órdenes religiosas y la actuación de la Inquisición. Además, la implantación a partir de 1472 de la imprenta en la Península incrementará la impresión de obras en castellano que, entre 1510 y 1520 , se iguala con las obras en catalán (Camps i Perarnau, 2008: 375, 383). Esta circunstancia tuvo especial incidencia en Valencia desde 1510, año de la publicación en la imprenta de Jorge Costilla del primer libro en castellano, Suma de todas las crónicas del mundo, traducido por Narcis Viñoles a partir de la traducción toscana del Supplementum chronicarum orbis ab initio mundi de fray Jacobus Philippus Bergomensis (Camps i Perarnau, 2008: 98). A medida que avanza el siglo XVI el número de libros impresos en catalán es inferior a los publicados en castellano, aunque la lengua administrativa siga siendo el catalán (Beas Teruel, 2009: 200).

En este período se documentan algunas traducciones de obras castellanas al catalán (Pujol, 2004: 647-648), que no tendrán continuidad en el siglo Xvi: el mallorquín Francesc Prats vertió la Visión deleytable de Alfonso de la Torre (compuesta hacia 1440 pero no publicada hasta 1485 en Burgos), que salió antes que el original (Visió delectable, 1484), y el valenciano Bernardí de Vallmanya tradujo la Cárcel de amor (1492) de Diego de San Pedro, que apareció impresa en Barcelona por Juan Rosenbach en 1493. En la dirección catalán-castellano (Chieregato y Gallén, 2009: 200), encontramos el Llibre dels Àngels (1392) de Francesc Eiximenis, traducido por Miguel de Cuenca y Gonzalo Ocaña como Libro de los santos ángeles (Burgos, 1490; reimpreso en 1516), y la primera traducción, anónima, del Tirant lo Blanch (Valencia, 1490), de Joanot Martorell, que salió en Valladolid en 1511, editada por Diego de Gumiel, con el título de Tirante el Blanco.

Por lo que respecta a Portugal, la supremacía medieval del gallego-portugués como lengua poética fue disminuyendo a lo largo del siglo XV ante la mayor presencia del castellano que ya es usado por el setenta por ciento de los poetas en el Cancioneiro Geral de Garcia de Resende (1516). Entre los factores que explican esta influencia podemos citar los abundantes matrimonios entre miembros de la realeza de España y Portugal en el contexto de una política que buscaba la constitución de una monarquía única católica; 
94 el intercambio cultural de estudiantes, profesores, confesores y escritores inherente a las relaciones entre ambas cortes, y el prestigio del castellano como lengua literaria y medio de divulgación internacional.

El impresor más importante en la transición del siglo XV al XVI fue el alemán Valentim Fernandes o Valentim de Moravia. En 1495, ocho años después de la introducción de la imprenta en Portugal, se estableció en Lisboa donde desarrolló una intensa actividad tipográfica hasta su muerte en 1518 o 1519. Como parte del bilingüismo reinante en los medios cultos lisboetas, editó la Glosa famosissima de las Coplas de Jorge Manrique y los Proverbios del marqués de Santillana en 1501, y tradujo al portugués, a partir del original castellano de Andrés de Li (Zaragoza, 1492), el Reportório dos tempos (1518) que tuvo doce reimpresiones en el siglo XVI. Asimismo, el proemio que escribió para su traducción del Livro de $\mathrm{Ni}$ colao Veneto, que publicó junto al Livro de Marco Paulo en 1502, traduce en buena parte el prólogo que Alfonso de Palencia escribió en 1457 para su Batalla campal de los perros contra los lobos. Este hecho confirma la circulación en la península Ibérica de un conjunto de ideas que planteaban desde el siglo xv las dificultades de traducir del latín al vulgar y defendían la transmisión del sentido. Además, el Livro de Marco Paulo, editado por Fernandes en 1502, sirvió de base para la traducción castellana de Rodrigo Fernández de Santaella publicada en Sevilla en 1503 (Sabio Pinilla y Fernández Sánchez, 2001).

\section{TRADUCCIONES ENTRE LENGUAS PENINSULARES EN EL SIGLO XVI}

A lo largo del primer tercio del siglo XVI surge en Europa un movimiento de defensa de las lenguas vernáculas que fue consolidándose hasta sustituir al latín. En el caso de España y Portugal, la dignificación del vernáculo coincide con sus empresas nacionales y llega a identificarse con el poder político, como parece presagiar Antonio de Nebrija en el prólogo de su Gramática castellana (1492) al comentar que «siempre la lengua fue compañera del imperio». Esto es bien patente en la primera gramática de la lengua portuguesa (Grammatica da lingoagem portuguesa, 1536) de Fernão de Oliveira, en la que se defiende la expansión ultramarina del portugués y su enseñanza como forma de asegurar la gloria de la nación. Por su parte, en la Grammatica da lingua portuguesa (1540) y en el Diálogo em louvor da nossa linguagem que la acompaña, João de Barros justifica la superioridad del portugués sobre las demás lenguas romances por su mayor parecido con el latín, en referencia indirecta al castellano que será la lengua que se imponga en este siglo.

El castellano irá ganando presencia tanto entre los letrados de Cataluña y Valencia como en la corte de Portugal y esa hegemonía como lengua meta y lengua intermedia de traducción repercutirá en el intercambio cultural y, por consiguiente, en las traducciones de obras escritas en lenguas peninsulares. Las condiciones que favorecen la función de fuente del sistema literario castellano en la Península obedecen a razones de tipo político y de prestigio: la expansión imperial convierte al español en lengua diplomática e instrumento de comunicación en la esfera administrativa y entre las clases cultivadas. Esta situación coincide en el tiempo con el desarrollo del portugués como lengua literaria: además de Gil Vicente, que adoptó el castellano en doce de sus autos y mezcló ambas lenguas en dieciséis, fueron bilingües, entre otros, Sá de Miranda, Luís de Camões y Jerónimo Corte-Real. En el caso del catalán, se ha fijado el año 1560 para señalar el predominio del monolingüismo entre los escritores valencianos que antes alternaban obras en castellano y en catalán (Camps i Perarnau, 2008: 377). 
La práctica de la autotraducción refleja bien la supremacía del castellano en el contexto político-cultural del siglo XVI. En 1546 el dominico Pere Antoni Beuter, primer cronista del Reino de Valencia, traduce del valenciano al castellano su Primera part de la Història de València (1538) «por el respeto del provecho común y divulgación mayor en toda España» (Santoyo, 2010: 370); ya la segunda parte, Coronica general de España y especialmente de Aragon, Cathaluña y Valencia, se publicó en castellano en 1551, «probablemente impulsado por el éxito de la traducción que había hecho en español» (Escartí, 2010), impresa como las anteriores en Valencia por Joan Mei. Quizá por influencia de Beuter (Gómez Bayarri, 2015: 4), Rafael Martí de Viciana publicó en castellano la Crónica de la ciudad de Valencia y su reino (1564-1566), que había redactado previamente en valenciano. Estos ejemplos muestran que el cambio de lengua era un signo de los tiempos en el ámbito del catalán y que el castellano se usaba en la producción erudita y en el mercado editorial no solo como medio de divulgación, sino también con una intencionalidad política en el marco de una monarquía única que iba imponiéndose en la Península (Escartí, 2010).

El deseo de divulgación, nacional e internacional, movió a Luis Pons de Icart a traducir al castellano el Libro de las grandezas y cosas memorables de la ciudad de Tarragona (Lérida, 1573), que había compuesto «en su lengua natural catalana», pese a ser "poco versado» en castellano y «no porque tenga yo por mejor lengua esta que la Catalana ni que otras: mas como sea natural del inuitissimo rey Philipe señor nuestro, esta mas usada, en todos reynos». No obstante, el autor-traductor se ve en la obligación de pedir perdón al lector por haber renunciado a la lengua materna para escribir en lengua ajena: «Y si me culpas porque escriuo en lengua agena esso quiero yo que me perdones pues ni yo podía en otra manera seruirte ni pagar la obligación que tẽgo e deuo a mi patria» (Pons de Icart, Prólogo al lector, 1573).

Por motivos parecidos, el portugués Pedro $\mathrm{Nu}$ nes, matemático y cosmógrafo real, publicó en 1567 el Libro de algebra en arithmetica y geometria en castellano, obra que había escrito en portugués hacia 1534 , porque «o bem quanto mais comum e universal, tanto é mais excelente, e porque a língua Castelhana é mais comum em toda Espanha que a nossa» (Fernández Sánchez y Sabio Pinilla, 2003: 217), palabras que refrendan la centralidad del castellano en «toda Espanha», expresión sinónima de península Ibérica.

Las justificaciones dadas por estos traductores en los prólogos de sus traducciones confirman la hegemonía del castellano en el polisistema peninsular a partir de la segunda mitad del siglo XVI no solo como vehículo de comunicación en los niveles cultos catalanes y portugueses, sino también como medio de difusión cultural. De este modo, las traducciones de obras castellanas al catalán y al portugués prácticamente desaparecen y, en sentido contrario, con las debidas reservas, las traducciones de obras catalanas y portuguesas al castellano ocupan un lugar secundario, como bien señala Josep Pujol para el catalán:

A medida que el castellano ganaba espacios como lengua del poder y como lengua literaria en las cortes aristocráticas y en los núcleos intelectuales de Cataluña y Valencia, y a medida que escritores catalanes producían en castellano o autotraducían sus propias obras a esta lengua y las capas más alfabetizadas de la sociedad catalana podían leerla, el intercambio cultural la traducción [sic] en una u otra dirección perdía parte de su significado².

2 Véase, Josep Pujol, «La traducción entre lenguas vernáculas (catalán y castellano) en la Edad Media», en Francisco Lafarga y Luis Pegenaute (eds.), DHTE: Diccionario histórico de la traducción en España, versión electrónica. Disponible en: http://phte.upf.edu/hte/edad-media/pujol/. 


\subsection{Traducciones del catalán al castellano}

Si las traducciones de obras castellanas al catalán son casi inexistentes en este siglo, en la dirección catalán-castellano encontramos notables excepciones como, por ejemplo, las traducciones de las poesías de Ausiàs March.

La mayoría de las traducciones del catalán al castellano en el siglo XVI son obras medievales de tema religioso, alegórico o histórico. Es el caso de la leyenda sobre la pasión de Cristo $G a$ maliel, compuesta en la segunda mitad del siglo XIII por el obispo san Pedro Pascual, que Juan de Molina tradujo en 1522 basándose en el texto que él mismo había editado en catalán; o la Verger de la Sacratíssima Verge Maria (1494) de Miguel Pérez, que tuvo varias traducciones en castellano y que Molina tradujo en verso como La vida y excelencias y milagros de la sacratissima Virgen María (Sevilla, 1525) (Simón Díaz, 1992: 118, 120). El Llibre de les dones de Francesc Eiximenis, especie de manual de instrucción de mujeres escrito probablemente entre 1387 y 1392, se publicó en Valladolid en 1542 con el título de Carros de las donas en traducción anónima que se ha atribuido al padre franciscano Carmona, confesor de Adriano VI (Clausell Nácher, 2005). La obra de Ramón Llull (h. 1232-1316) empezó a difundirse en el mundo hispánico a través de la traducción a mediados del siglo XVI, aunque su divulgación en español no se da hasta el siglo XVII. Su poema elegíaco el Desconhort (1295) fue traducido por Nicolau de Pacs i Sureda como Desconsuelo (1540) y se considera el primer libro impreso en castellano en Mallorca (Beas Teruel, 2009: 200). De finales del siglo XVI es la traducción de la Crónica de Ramón Muntaner, redactada entre 1325 y 1328. Esta crónica, una de las obras cumbres de la Edad Media europea, narra la historia de la expansión catalano-aragonesa por el Mediterráneo. Fue traducida por Miguel
Monterde sobre la edición de 1558 de la Real Biblioteca del Monasterio de El Escorial (Alaix i Gimbert, 2015: 171).

También el castellano sirvió de lengua intermedia a obras como el Spill de la vida religiosa (Barcelona, Juan Rosenbach, 1515), atribuida al fraile jerónimo Miquel Comalada, que se conoció en español con el nombre de su protagonista, El Deseoso, desde su primera traducción (Sevilla, Juan Cromberger, 1533) (Esteva de Llobet, 2019). Este tratado de espiritualidad, compuesto en forma de novela alegórica, fue traducido a numerosos idiomas a partir del español que harán de esta secuela literaria de Lull un éxito en Europa: tuvo dos ediciones en catalán, doce en español y holandés, siete en alemán, seis en latín, cuatro en inglés, tres en italiano y una en polaco, gaélico (Irlanda), danés y portugués (Valsalobre, 2001: 11, nota 2).

\subsubsection{Las traducciones de la poesía de Ausiàs March}

En este contexto, surgen las traducciones de las poesías de Ausiàs March (1397-1459), «sin duda el mejor poeta lírico europeo del siglo XV» (Micó, 2004: 199), introductor del primer petrarquismo y uno de los poetas de la literatura catalana más traducidos en español.

La primera traducción, del valenciano Baltasar de Romaní, apareció en Valencia en 1539. Se trata de una traducción bilingüe (curiosamente es también la primera edición del original catalán de Ausiàs March) y parcial (solo cuarenta y seis poemas, la mayoría de forma fragmentaria, cuya traducción se intercala entre las estrofas en catalán), que contiene algunos errores y se somete a la autocensura de carácter religioso. Romaní quiso ser fiel a la métrica y a la rima del original y tradujo literalmente el decasílabo provenzal, característico del catalán y dominante en la obra de March, renunciando a usar el verso de 
arte mayor castellano o el endecasílabo italiano, en fase de aclimatación en la Península. El resultado se considera muy irregular y, en realidad, los decasílabos provenzales son dodecasílabos, como puede verse en la traducción del poema LXXVII de las ediciones catalanas modernas:

$\begin{array}{cc}\text { No pot mostrar } & \text { le món menys pietat } \\ \text { com en present } & \text { de sobre mi pareix: } \\ \text { tot amor fall, } & \text { sinó a mi mateix } \\ \text { de enveja és } & \text { tot lo món conquistat. } \\ \text { Hom sen afany } & \text { no vol fer algún bé: } \\ \text { ¿com lo fará } & \text { contra si, amb gran cost? } \\ \text { Cascun cor d'hom } & \text { yo veig pus dur que post; } \\ \text { algú no.s dol } & \text { si altre null mal té. } \\ \text { No puede el cielo } & \text { ser más despiadado } \\ \text { de lo que agora } & \text { tan claro en mi paresce. } \\ \text { Si no en mi mismo } & \text { en todo amor fallesce; } \\ \text { el mundo es } & \text { de envidia conquistado. } \\ \text { Sin gran trabajo } & \text { no haze bien alguno } \\ \text { como le hará } & \text { ai contra síle haze. } \\ \text { El mal ajeno } & \text { no duele ni desplaze, } \\ \text { ni hay piedad } & \text { en coraçón alguno. }\end{array}$

La versión de Romaní se reeditó en Sevilla en 1553, sin el texto en catalán, y tuvo ediciones parciales en 1562 y 1579.

La segunda traducción del portugués Jorge de Montemayor es de 1560 y apareció también en Valencia. Es una versión respetuosa con el original, aunque, como Romaní, Montemayor autocensura los pasajes religiosos y no aclara los pasajes oscuros del original. Es considerada la mejor traducción de la poesía de March del Siglo de Oro y tuvo reediciones en Zaragoza en 1562 (que incluye once poemas de la traducción de Romaní no traducidos por Montemayor) y en Madrid en 1579. El traductor recoge noventa y siete poemas que traduce en octavas reales de endecasílabos heroicos, adaptando a March a los moldes poéticos renacentistas. Asimismo, moderniza el léxico, dulcifica la sintaxis y evita reproducir las características formales del poeta valenciano por lo que se trata, en muchos casos, de una adaptación. Veamos, a modo de ejemplo, la traducción de la primera estrofa del poema LXXXIX, el XXIV en la edición de Montemayor, en la que desaparece la traducción del primer verso y acerca a March a la estética amatoria del Renacimiento:
Cervo ferit

aytant com yo

al gran repòs, passar no pusch

Mol me ve tart comprat molt car

e tart o breu si per la mort no desija la font esser a vós pressent; de mon contentament sinó por aquest pont. lo jorn tant desijat per dolorós sospir so cert que deu venir camí no m'es tancat.
Con sed el caminante no dessea, lo medio que yo a vos, la clara fuente; al bien qu'el alma y cuerpo señorea, jamás podré passar por otra puente; el día tarda mucho, aunque assí sea, y cómprolo a mi costa caramente mas él ha de allegar, tarde o temprano, si muerte no le estorva y va a la mano.

Sin menospreciar el papel que tuvo en la divulgación de la poesía de March la lectura del original en catalán y la traducción de Romaní, mucho más literal, la traducción de Montemayor es tenida como la principal fuente de conocimiento del poeta valenciano en los siglos XVI y XVII.

De las versiones de poemas sueltos de Ausiàs March destacan las del poema XXXIX y las dos primeras estrofas del poema IV hechas por el Brocense hacia 1580. Aún se documenta a finales del siglo XVI otra traducción, de escaso valor, conocida como «anónimo del Escorial» que depende de la de Romaní (Nogueras Valdivieso y Sánchez Rodrigo, 1999; Sánchez Rodrigo y Nogueras Valdivieso, 2000). 


\subsection{Traducciones entre portugués y castellano}

Durante el siglo XVI se publicaron en Portugal ciento cuarenta traducciones, incluidas reimpresiones y reediciones, en su mayoría obras espirituales escritas en latín (Gonçalves Rodrigues, 1992) ${ }^{3}$. Del total de traducciones, solamente seis fueron del castellano y de tema religioso o de contenido astronómico relacionado con los descubrimientos: Reportório dos tempos (1518, traducción de Valentim Fernandes de la obra de Andrés de Li); Arte pera bem confessar (1537); Compendio da doctrina christãa de fray Luis de Granada (1559); Breve aparelho para receber o sanctissimo sacramento, tirado das meditações de frey Luis de Granada (1574); Reportório dos tempos (1582, traducción de André do Avelar de la Chronographia o reportorio de los tiempos de Jerónimo Chaves); Flos Sanctorum de Alonso de Villegas (1598, traducción de Simão Lopes).

Esta escasez de traducciones y de tipos de obras traducidas es consecuencia, entre otras razones, del bilingüismo luso-castellano, «asimétrico o diglósico» (Dasilva, 2017: § 6), que dispensaba la traducción de obras escritas o ya traducidas en castellano ${ }^{4}$. La traducción podía suponer incluso un dilema: Duarte de Resende decide no traducir

3 Entre las pocas traducciones de obras científicas destacan el Tratado da esfera de Sacrobosco y el primer libro de la Geografia de Ptolomeo (1537), a las que el traductor Pedro Nunes añade algunos comentarios para facilitar su comprensión y otros escritos suyos de náutica. En cuanto a la literatura clásica, con excepción de los tratados de Cicerón y de la Tragédia da vingança que foi feita sobre a morte del rei Agaménom o Tragédia de Orestes de Anrique Aires Vitória (1536, reimpresa en 1555) o el Manual de Epicteto, en versión de António de Sousa (1594, reimpreso en 1595), no se documentan hasta el primer tercio del siglo XVII traducciones completas de Virgilio o adaptaciones y comentarios extensos de Horacio.

4 En el siglo XVI se publicaron en Portugal ciento veintiséis obras en castellano (Anselmo, 1926), número casi igual al total de traducciones. los tratados ciceronianos De officiis y De senectute porque estaban en castellano, subordinando el provecho de su traducción a lo superfluo del empeño o a la posible sospecha de plagio, muestra evidente del conflicto lingüístico provocado por la situación de bilingüismo (Fernández Sánchez y Sabio Pinilla, 2003: 222).

Según Dasilva (2017: § 18), «la literatura española entra en Portugal mediante la circulación del texto original y la traducción alógrafa, mientras que la literatura portuguesa arriba a España gracias a la creación alófona, la autotraducción y la traducción alógrafa». Fray Luis de Granada es un buen ejemplo para calibrar cómo la literatura española circulaba en Portugal preferentemente a través del texto original: sus obras tuvieron hasta 1700 dos ediciones en latín, dieciséis en español y cuatro en portugués (Gonçalves Rodrigues, 1992: 28). Por otra parte, antes de la versión portuguesa de 1670, la Imitación de Cristo de Tomas de Kempis circuló impresa desde mediados del siglo XVI en la versión castellana de fray Luis de Granada y fue reeditada al menos siete veces hasta 1649.

En cuanto a la literatura portuguesa en España, encontramos casos de traducción alógrafa como, por ejemplo, los tratados Da pintura antiga (1548) y Do tirar pelo natural (1549) de Francisco de Holanda, traducidos por el también pintor portugués Manuel Denis en 1563 con el título De la pintura antigua (Moreira, 2017). La novela de caballerías Palmeirim de Inglaterra, de Francisco de Moraes, escrita entre 1540 y 1544, fue traducida anónimamente en 1547 y 1548 y sirvió de versión intermedia para las traducciones francesa, inglesa e italiana (Dasilva, 2017: § 40). Finalmente, las dos partes de la Imagem da Vida Cristã (Coímbra, 1563; Lisboa, 1572) de frei Heitor Pinto, fueron traducidas en 1571 (primera parte, Zaragoza, por traductor anónimo) y en 1580 (segunda parte, Alcalá, por Gonzalo de 
Illescas) (Ricard, 1972: 437). Pero, sin duda, la máxima expresión de la traducción de este par lingüístico ocurrió en los últimos veinte años del siglo XVI con la publicación de tres traducciones en octava rima de Os Lusíadas (1572) de Luís de Camões (h. 1524-1580).

\section{LAS TRADUCCIONES DE OS LUSÍADAS}

Os Lusíadas fueron publicados en 1572 en la imprenta lisboeta de António Gonçalves. Se trata de un poema épico nacional, de imitación clásica, cuyo principal modelo es la Eneida de Virgilio. El tema central de esta epopeya renacentista es el descubrimiento de la ruta marítima a la India por Vasco de Gama (1497-1498), pero los auténticos protagonistas son los portugueses (los lusíadas, 'los lusitanos' o 'los hijos de Luso') y la historia de Portugal: su pasado (primeros reyes), el presente (viaje de Vasco de Gama a la India) y el futuro (la secuencia de los gobernadores y virreyes de Oriente). En 1578, seis años después de la publicación del poema que está dedicado al rey don Sebastián, el joven monarca moría en la batalla de Alcazarquivir. El gobierno de la nación recayó en el Cardenal don Enrique, único hijo vivo de Manuel I, que falleció en 1580. Ese mismo año Felipe II anexionó Portugal alegando su derecho a la sucesión por ser nieto materno de Manuel I y tío de don Sebastián, lo que dio inicio al período conocido como Unión Ibérica o monarquía dual (1580-1640).

En este ambiente aparecieron tres traducciones del poema en verso castellano, dos en 1580 y una tercera en 1591, como si la monarquía española quisiera adueñarse de la obra símbolo de Portugal. De hecho, se ha propuesto sin prueba convincente la participación directa de Felipe II en estas tres traducciones, aunque la única dedicada al rey es la de 1591. Pero como ha argumentado Dasilva $(2014,2017)$ existe una relación evi- dente, no exenta de implicaciones ideológicas, entre la anexión de Portugal y la aparición de dos traducciones casi simultáneas del poema y de una tercera once años después, que ayudaron a diseminar "a través del español la trascendencia política y cultural del nuevo territorio de la Monarquía Hispánica» (Dasilva, 2017: § 45).

Las traducciones de 1580 estuvieron patrocinadas, respectivamente, por las universidades de Alcalá de Henares y de Salamanca: la primera es obra del portugués Benito Caldera y fue impresa por Juan Gracián ${ }^{5}$; la segunda, del andaluz Luis Gómez de Tapia, fue publicada poco después por Juan Perier ${ }^{6}$. Parece que hubo cierta competencia entre ambas universidades por $\mathrm{pu}$ blicar antes la traducción ${ }^{7}$, según se desprende de las quintillas que Pedro de Vega le dedica a Tapia para consolarlo por haber salido en segundo lugar: «Que si os tuuieron del pie / Para ganaros la mano / Al salir (como ello fue) / Lleuese el salir temprano; / Vos lleuareys el porque». La tercera traducción, del portugués Henrique Garcés, fue elaborada en Perú pero apareció en Madrid en 1591, impresa por Guillermo Drouy ${ }^{8}$.

Este esfuerzo de divulgación del poema, debido sobre todo a traductores portugueses, cul-

5 Los Lusíadas de Luis de Camões, traducidos por Benito Caldera. Alcalá de Henares: Juan Gracián, 1580. Disponible en la Biblioteca Digital Hispánica de la BNE: http://bdh-rd. bne.es/viewer.vm?id=0000121365\&page $=1$ y en la Biblioteca Nacional Digital de Portugal: http://purl.pt/23629.

6 La Lusíada de Luis de Camões, traducida por Luis Gómez de Tapia. Salamanca: Juan Perier, 1580. Disponible en la Biblioteca Digital Hispánica de la BNE: http://bdh-rd.bne.es/ viewer.vm?id=0000080798\&page $=1$ y en la Biblioteca $\mathrm{Na}$ cional Digital de Portugal: http://purl.pt/23635.

7 Y rapidez, lo que puede explicar que las traducciones de Caldera y de Tapia no pasasen la censura eclesiástica y que la traducción de Tapia saliese sin la aprobación y la licencia preceptivas.

8 Los Lusíadas de Luis de Camões, traducidos por Henrique Garcés. Madrid: Guillermo Drouy, 1591. Disponible en la Biblioteca Nacional Digital de Portugal: <http://purl.pt/23641>. 
100 mina un año antes de la restauración de la independencia de Portugal con la edición comentada del también portugués Manuel de Faria e Sousa, que fue publicada en Madrid en 1639, después de veinticinco años de trabajo ${ }^{9}$. Este comentarista fue además el primero en ofrecer una traducción en prosa del poema. El monumental trabajo de Faria e Sousa convirtió a Camões en clásico español y ayudó a que fuese conocido e imitado por los escritores del siglo XVII.

\subsection{La traducción de Benito Caldera}

Según Domingo Garcia Peres (1890: I, 85), Caldera «pasó desde joven a Castilla, en donde residió, y al fin profesó en el Convento de San Felipe el Real de frailes agustinos, en Madrid». Parece que fue «muy instruido en las letras humanas y principalmente en los preceptos del Arte Poética» y que "supo con suma perfección la lengua castellana» (Barbosa Machado, 1966: I, 500). Caldera debía ser muy joven cuando tradujo $O s$ Lusíadas: Pedro Laínez en la Epistola al lector señala que tenía "pocos años» y lo corrobora Pedro de Vega en los preliminares de la traducción de Tapia al referirse a Batto, nombre poético de Caldera: «Ni negueys que fue buen zelo / Querer Batto en edad tierna / Illustrar su nombre y suelo / Y de su lengua paterna / Transplantarse al nueuo cielo".

La traducción fue aprobada el 17 de marzo por el humanista valenciano Fadrique Furió Ceriol y obtuvo privilegio real el 26 de marzo, por lo que salió aún en vida de Camões que murió el 10 de junio de 1580. El privilegio de Felipe II, que concede a Caldera la venta exclusiva de su traducción

9 Lusíadas de Luis de Camoens, comentadas por Manuel de Faria e Sousa. Madrid: Juan Sánchez, 2 tomos, 1639. Disponible en la Biblioteca Digital Hispánica de la BNE: http://bdh-rd. bne.es/viewer.vm?id=0000042388\&page $=1 \mathrm{y}$ en la Biblioteca Digital Nacional de Portugal: <http://purl.pt/23676>. por veinte años, lo considera «libro prouechoso para los professores de historia y nauegacion», una valoración extraestética que entiende el poema como «enciclopedia». Del mismo modo, Garcés dirá en el soneto que cierra su traducción: «Y mucho más de vna Enciclopedia / como esta, que de si Luys quiso darnos», para recalcar los múltiples valores de Os Lusíadas.

De los textos preliminares destaca la Epístola al lector de Pedro Laínez, quien hace una enardecida defensa del traducir y considera toda traducción "prouechosa y digna de ser estimada y encarescida» porque divulga en otra lengua las enseñanzas que solo unos pocos disfrutan en la suya. Elogia al traductor, «por comunicarnos el prouecho que de entenderla y de imitarla se nos sigue», y previene contra la engañosa facilidad de traducir entre dos lenguas que difieren poco, notando que "por estar en este engaño estimase en menos el trabajo que en esta traducion tan bien hecha ha tenido Benito Caldera». Laínez equipara al traductor con el autor, "a el sele deue no menos en la traduciõ que al primer autor en la obra», y señala el método seguido por Caldera: «no ha ydo tan atado ala letra, quanto a lo mas essencial de la sentencia». Finalmente, invita a los lectores a que reciban de buen grado la traducción de un ingenio claro y de «pocos años».

Completan los preliminares seis sonetos de poetas de Madrid que celebran la trascendencia de la traducción en la difusión del poema.

\subsection{La traducción de Luis Gómez de Tapia}

Luis Gómez de Tapia es el único traductor no portugués del poema hasta Lamberto Gil en 1818. Según Nicolás Antonio (2006 [1783]: I, 541), fue granadino y autor de La descripción de Aranjuez y del Pardo, égloga pastoril recogida por Gonzalo Argote de Molina en el Libro de la Montería (Sevilla, 1582). Sin embargo, en el títu- 
lo de la portada de su traducción aparece como «vezino de Sevilla».

La traducción está dedicada al futuro cardenal Ascanio Colonna, que estaba matriculado en la Universidad de Salamanca en los estudios de Filosofía y Teología en el curso 1579-1580. En esta dedicatoria Tapia formula la primera universalización del poema: Os Lusíadas están escritos «en tã alta poesia, que se llega a la Eneyda, vence a la Thebayda y es poco menos que la Illiada, o Odisea de Homero». Además, justifica su traducción «en lengua clara aunque en estylo baxo» porque la obra era "de pocos de los nuestros buscada, de menos leyda, y casi de ninguno entendida».

De los textos que acompañan la traducción sobresalen el Prólogo al lector de Francisco Sánchez de las Brozas, el Brocense, y la primera poesía impresa de Luis de Góngora. El Brocense contrapone la grandeza del poeta verdadero a la mediocridad del coplista o versificador, pues para ser poeta, como Camões, se necesitan tantas cualidades que en un siglo hay «dos o tres poetas en cada nacion» o incluso ninguno. Considera el poema un tesoro que "no era razon que en sola su lengua se leyese» y agradece al traductor su trabajo de difusión en castellano, por «comunicarlo a su lengua Castellana, y por consiguiente a la misma Portuguesa, a toda Italia, y a las demas naciones, que son muchas, que de la lengua Castellana se precian». Opina que Tapia tiene las cualidades necesarias para traducir el poema "por ser muy acabado poeta Latino y Español, y entender muy biẽ la lengua Portuguesa» y explica el método seguido: procuró «no solo traduzir la sentencia, pero darnos el sentido y vigor de las palabras». Para corroborarlo, se apoya en las autoridades de Horacio y, sobre todo, de Cicerón sumándose a la tradición iniciada por san Jerónimo en su Epístola a Pamaquio (h. 395), aunque el Brocense advierte pertinentemente que muchos hacen una mala interpretación del verso de Horacio:

\begin{abstract}
Y que esto sea el verdadero officio del interprete, sacase de Horacio en su arte poetica, do dize. Nec verbum verbo curabis reddere fidus Interpres, que quiere dezir: No quiero que seas como fiel Interprete, cuyo officio es dar palabra por palabra, porque el que imito a otro, basta le tomar y traducir la sentencia y concepto. Este verso de Horacio ha engañado a muchos entendiendo que quiere dezir otra cosa [...] Harto mejor declaro el officio del buen interprete el mismo Tulio en el libro de Optimo genere interpretandi [sic][...] Claramente dize aqui Tulio que no vso de officio de interprete, sino de orador, porque realmente el fiel interprete esta obligado ansi a las palabras, como a la sentencia: pero si por ventura la palabra que traduze, no se puede significar en la otra lengua por otra palabra, en tal caso se le da licencia que vse de muchas en lugar de vna.
\end{abstract}

Por último, recuerda que el traductor incluye unas «declaraciones breuissimas al fin de cada Canto», aunque podría haber hecho un "Comento» en que recogiese la mitología y las figuras del poema, pero no las trató «por ser cosa que para la nauegacion de las Indias importaua poco» y se contentó con "representarnos la elegancia de palabras del autor, y la contextura de la sentencia».

La traducción de Tapia incluye la primera poesía impresa de Góngora, escrita con diecinueve años cuando era estudiante en Salamanca. La poesía, altisonante y culta, sigue la estrofa de la Canzone de Petrarca Chiare, fresche e dolci acque, a la que añade las rimas esdrújulas (Asensio, 1980: 117) para realzar el canto heroico del poema: «Suene la trompa bellica / Del Castellano calamo / Dando le lustre y ser a las Lu- 
102 siadas ${ }^{10}$; / Y con su rima angelica / En el celeste talamo / Encumbre su valor sobre las Hyadas».

Las restantes composiciones poéticas exaltan la universalización de Os Lusíadas gracias a la traducción en una evidente apropiación del poema en castellano. Cierran los preliminares las quintillas de Pedro de Vega en las que consuela a Tapia por haber salido su traducción en segundo lugar y un Catálogo de los Reyes de Portugal desde el Conde don Enrique hasta 1580 «en que la mayor parte de Portugal está Subjecta a la Magestad del Rey Don Phelippe nuestro Señor».

\subsection{La traducción de Henrique Garcés}

Garcés nació en Oporto en 1525 (Lohman Villena, 1969), pero vivió la mayor parte de su vida en Perú donde sirvió a la Corona desarrollando una serie de actividades metalúrgicas. En el campo literario, tradujo del italiano Los sonetos $y$ canciones de Petrarca, traducción que divulgó en Lima la lírica petrarquista; del latín tradujo Sobre el Reino y de la institución del que ha de reinar y de cómo debe haberse con los súbditos, y ellos con él, de Francisco Patrizi, y del portugués Los Lusíadas de Camões. Las tres traducciones, financiadas por Garcés, están dedicadas a Felipe II y fueron publicadas por Guillermo Drouy en Madrid en 1591.

Io La traducción natural de Os Lusíadas en español es Los Lusíadas. Sin embargo, a lo largo de la historia, encontramos otras traducciones del título: Luis Gómez de Tapia fue el primero que tradujo La Lusíada, por comparación con La Eneida, e inauguró una tradición (Lusíada o La Lusíada), seguida, por ejemplo, en la edición comentada de Faria e Sousa. Las variantes Las Lusíadas o Lusíadas son usadas, entre otros, por Faria e Sousa en el frontispicio de su edición o por el propio Góngora en su canción. Menos frecuentes han sido las formas Luisíada o Luisíadas, que derivan el título del poema del nombre del poeta, y Los Lusiades, por comparación con Enéades, que figura en el albarán real de la traducción de Garcés (Sabio Pinilla, 1990: 131-132 y nota 109).
El albarán real, expedido por Juan Vázquez el 31 de enero de 1591, corrobora que Garcés era «vezino de Lima en el Peru» y que allí había traducido «los Lusiades del Camões, que eran muy vtiles e prouechosos» y se le concede licencia de impresión por veinte años. La aprobación de fray Pedro de Padilla para imprimir la traducción, fechada el 20 de octubre de 1590, señala que «no ay en el cosa que sea contra la Fe ni las buenas costumbres», al contrario, encuentra «mucha erudicion y variedad de cosas vtilissimas, en muy buen estilo muy elegante y proprio». Esta actitud contrasta con lo ocurrido en la segunda edición portuguesa de Os Lusíadas de 1584, reeditada en 1591, que sufrió los rigores de la censura inquisitorial.

Diego de Aguilar, escritor peruano amigo de Garcés, es el único poeta que colabora en los versos preliminares además del propio traductor que dedica dos sonetos a Felipe II e incluye un tercero en respuesta a Aguilar para agradecerle que sea "guia en tal jornada». Cierra la traducción otro soneto de Garcés en el que certifica que su versión iba dirigida al Nuevo Mundo: «Mas porque no quedassen sepultados / hechos y versos tanto soberanos / en solo Portugal, mis toscas manos / los dan al nueuo mundo trasladados».

\subsection{Valoración de las traducciones}

Manuel de Faria e Sousa, tal vez para justificar la suya en prosa, consideraba las traducciones del siglo XVI «tan malas todas, que exceden la infelicidad de toda traducion que se haze de escritura en verso» (Advertencias, VI, 1639). También Lamberto Gil, traductor del poema en 1818, mostró su disconformidad con estas versiones:

[...] porque los que las hicieron muchas veces parece que no entendieron bien al poeta, $y$ le hicieron decir cosas muy ajenas de las que él había dicho, porque su versificación es tan dura que en ningu- 
na de ellas hay media docena de octavas que puedan leerse sin lastimar los oídos del que las escucha, y porque están llenas de voces que, o no son castellanas, o son bajas y poco dignas de la poesía épica (Gil, 1911 [1818]: 3-4).

No obstante, tuvo la preocupación de cotejar su traducción con estas versiones, siendo la traducción de Tapia la que más versos le presta. Más cerca de nuestros días, Eugenio Asensio considera que Caldera «es fiel, literal, en la misma estrofa del original, con el que a menudo se corresponde verso a verso»; de Tapia opina que es «menos literal» $\mathrm{y}$ «modifica no sin violencia las expresiones camonianas, buscando fórmulas originales y cometiendo, por la rapidez con que trabaja, no pocas infidelidades»; de Garcés apenas comenta: «su versión no mejora las anteriores, ni influyó en el mundo literario» (Asensio, 1980: 115). De nuestro análisis (Sabio Pinilla, 1983), se confirma que la traducción de Caldera es la que sigue más de cerca el poema, manteniendo siempre que puede una correspondencia verso a verso, pero a costa de sacrificar el valor poético; en el extremo opuesto, se encuentra la traducción de Garcés, que recrea en exceso el poema y rebaja bastante el tono culto; entre ambas, se sitúa la traducción de Tapia, que altera muchos versos, quizá porque conociera la de Caldera (Goyri, 1880: 7), pero alcanza un equilibrio entre literalidad y recreación.

A pesar de las críticas, el valor histórico-literario de estas traducciones es muy importante y no solo porque apunten futuras tendencias de traducción. Las traducciones de Caldera, Tapia y Garcés muestran el valor del español como lengua de difusión internacional a finales del siglo XVI y son un buen ejemplo de la apropiación político-cultural realizada en castellano por traductores portugueses en los primeros años de la Unión Ibérica. La traducción de Caldera, que apareció en vida de Camões, presenta soluciones válidas para la fija- ción del texto crítico de Os Lusíadas; por su parte, la traducción de Tapia tiene el valor añadido de ser la primera anotada del poema y la traducción de Garcés, aunque publicada en Madrid, fue la primera que lo divulgó en América adelantándose en tres siglos y medio a la traducción (en prosa) de Gonzalo San Martín Lastra (Santiago de Chile, 1940). De la relevancia de estas traducciones dan fe los preliminares poéticos laudatorios, así como los prólogos y epístolas que son documentos preciosos para entender aspectos de la retórica de la época y la cuestión, siempre controvertida, de la traducción entre lenguas cercanas, consideradas tradicionalmente «fáciles» ${ }^{11}$. Por fin, pese a rebajar el tono culto del poema, las tres traducciones introdujeron gran cantidad de cultismos en español y ayudaron a universalizar Os Lusíadas antes de ser traducidos a otras lenguas ${ }^{12}$.

\section{RECAPITULACIÓN}

En este trabajo hemos ofrecido un panorama de las traducciones realizadas entre lenguas peninsulares en el siglo XVI. Hemos tomado el catalán y el portugués como lenguas de partida y el castellano como lengua de llegada, además de sus posibles combinaciones. El gallego, que tuvo un cultivo notable en la época medieval, desaparece del espacio peninsular como lengua literaria a partir del siglo XVI y el vasco comienza su andadura en la traducción a finales de ese siglo, por lo que ambos idiomas han quedado fuera de nuestro recorrido.

II Diez de los textos preliminares fueron recogidos por Dasilva (2006) en el primer volumen de su antología Babel Ibérico.

${ }^{12}$ La primera traducción inglesa, de Richard Fanshaw, es de 1655; la primera italiana, de Antonio Carlo Paggi, es de 1658. Hasta 1735 no encontramos la primera traducción conservada del poema en francés, obra de Duperron de Castera. En 1622 se había publicado la traducción latina de frei Tomé de Faria (Sabio Pinilla, 1990: 59-60). 
104 Las «traducciones intrapeninsulares» (Russell, 1985) se documentan en toda la Edad Media. Este fenómeno fue especialmente importante en el siglo XIV para el aragonés y el catalán, lengua esta que tuvo una posición central en el polisistema peninsular medieval y que, con el castellano, contribuyó a preparar la entrada del humanismo en la península Ibérica durante el siglo Xv.

En el paso del siglo XV al XVI, el castellano comienza a imperar en el mapa lingüístico peninsular hasta convertirse en la lengua principal. Ese papel hegemónico obedece a varias razones, entre ellas, la introducción de la imprenta, la política centralizadora de una monarquía que aspiraba a ser única y el prestigio del español como lengua de comunicación internacional. Los efectos serán visibles en Portugal y en las tierras de habla catalana a partir del primer tercio del siglo XVI.

El castellano se impone en el siglo XVI como lengua meta y como lengua intermedia de traducción, recurriendo en ocasiones el catalán y el portugués a la autotraducción. En cambio, las obras castellanas traducidas a las otras lenguas peninsulares asumen una posición muy periférica. La mayoría de las traducciones del catalán al castellano son de tema religioso, alegórico o histórico y proceden de la Edad Media; sin embargo, desde principios del siglo XVI no se documentan traducciones en dirección inversa lo que debe entenderse como resultado del predominio lingüístico del castellano en el polisistema peninsular quinientista.

Por su parte, el bilingüismo luso-castellano constatado en Portugal desde mediados del siglo $\mathrm{XV}$ repercutió en el fenómeno de la no traducción que tuvo como efecto la escasez de traducciones y la tardía traducción de obras clásicas griegas y latinas porque ya circulaban en castellano. A consecuencia de esta situación, como en el caso del catalán, las traducciones entre castellano y portugués ocuparon una posición secundaria en los intercambios culturales de ambos sistemas: la literatura española circuló en Portugal, sobre todo, a partir de la lectura del texto original y los textos portugueses circularon en España gracias a la llamada «traducción alógrafa» (Dasilva, 2017), hecho bien documentado en las traducciones de Os Lusíadas a las que hemos dedicado una atención especial por su valor histórico-cultural.

Desde un punto de vista estrictamente literario, las traducciones de las poesías de Ausiàs March y del poema de Luís de Camões constituyen los hitos de la traducción entre lenguas peninsulares en el siglo xvI. En ambos casos, podemos observar cómo el sistema castellano selecciona y se apropia de obras consideradas canónicas (March como modelo de una concepción personal del amor trovadoresco adaptada al estilo petrarquista y Camões como modelo de la poesía épica renacentista de influencia clásica y tema nacional), adecuándolas al sistema literario receptor y renovando el léxico culto. En estos y otros ejemplos, el castellano sirvió de vehículo de divulgación internacional y esa divulgación se debió, en gran medida, a traductores portugueses (Montemayor, Caldera o Garcés) quienes actuaron desde dentro del sistema literario castellano como transmisores de los dos poetas más importantes en catalán y en portugués de los siglos XV y XVI, respectivamente.

Por último, en relación con la progresión observada en los siglos XIV y XV, las traducciones entre lenguas peninsulares en el siglo XVI, aun constituyendo un fenómeno importante (Ruiz Casanova, 2018: 195), sufren cierto estancamiento y una reducción del número de lenguas implicadas en la traducción debido a la hegemonía del castellano. Esta circunstancia tuvo como principal contrapartida que las traducciones de obras castellanas al catalán y al portugués asumieran una posición muy periférica en el polisistema peninsular quinientista. 


\section{REFERENCIAS}

Alaix I Gimbert, Tània (2015): «Capitol 6: Manuscrits, edicions impreses i estudis», en VV.AA., Les cròniques catalanes, Barcelona: Departament de Cultura de la Generalitat de Catalunya, Biblioteca de Catalunya, 158-181.

Anselmo, António Joaquim (1926): Bibliografia das obras impressas em Portugal no século XVI, Lisboa: Biblioteca Nacional.

AnTonio, Nicolás (2006) [1783]: Bibliotheca hispana nova, tomo I, Alacant: Biblioteca Virtual Miguel de Cervantes, <http://www.cervantesvirtual.com/nd/ ark:/59851/bmcgfOq5>.

AsENSIO, Eugenio (1980): «Camões en la poesía española de los siglos xvı y xvII», Arquivos do Centro Cultural Português, 15, 111-132.

Barbosa Machado, Diogo (1966-1968) [1741-1759]: Biblioteca Lusitana, Coimbra: Atlântida (4 vols.).

BeAs Teruel, María Angustias (2009): «Transferencia léxica en las colocaciones con hacer y dar en el español de Mallorca desde la perspectiva diacrónica», en Laura Romero Aguilera y Carolina Juliá Luna (coords.), Tendencias actuales en la investigación diacrónica de la lengua, Barcelona: Universitat de Barcelona, 197-206.

Camps i Perarnau, Susana (2008): Diego de Gumiel, impressor de Tirant lo Blanch (1497) $i$ del Tirante el Blanco (1511), Barcelona: Universitat Autònoma de Barcelona (tesis doctoral), <https://hdl.handle. net/10803/283965>.

Chieregato, Chiara y Enric Gallén (2009): «Catalán al castellano, Traducción desde el», en Francisco Lafarga y Luis Pegenaute (eds.), Diccionario histórico de la traducción en España, Madrid: Gredos, 200-205.

Clausell NÁcher, Carmen (2005): Carro de las donas (Valladolid, 1542). Estudio premilinar y edición anotada. Barcelona: Universitat Autònoma de Barcelona (tesis doctoral), <http://hdl.handle.net/10803/4871>.

DAsIlva, Xosé Manuel (2006): Babel ibérico. Antología de textos críticos sobre la literatura portuguesa traducida en España, Vigo: Universidade de Vigo.

DAsILVA, Xosé Manuel (2014): «La evolución histórica de las traducciones españolas de Os Lusíadas», RevLet Revista Virtual de Letras, 54/1, 193-207, <https:// periodicos.fclar.unesp.br/letras/article/view/7828>.
DAsILVA, Xosé Manuel (2017): «La traducción literaria entre español y portugués en los siglos XVI y XVII», e-Spania, 27, doi: 10.4000/e-spania.26695.

EsCARTí, Vicent Josep (2010): «Narrar la historia remota de un país: Beuter y la Història de València (1538)», Espéculo. Revista de estudios literarios (Universidad Complutense de Madrid), 44, <http://www.ucm.es/ info/especulo/numero44/beuterva.html>.

Esteva de Llobet, Lola (2019): «El Desitjós o Spill de la vida religiosa (Barcelona, 1515). Un texto de referencia en la espiritualidad española del siglo XVI», en Christoph Strosetzki (coord.), Perspectivas actuales del hispanismo mundial. Volumen I: Medieval/Siglo de Oro / Teatro, Münster: Wissenschaftliche Schriften der WWU Münster, Reihe XII, Band 22.1., 113-133.

FAUlHABER, Charles B. (1995): «Sobre la cultura ibérica medieval: las lenguas vernáculas y la traducción», en José Manuel Lucía Megías (coord.), Actas del VI Congreso Internacional de la Asociación Hispánica de Literatura Medieval, Alcalá: Universidad de Alcalá, vol. I, 587-598.

Fernández SÁnchez, María Manuela y José Antonio Sabio Pinilla (2003): «El Humanismo renacentista y la traducción en Portugal en los siglos XVI y XVII», en José Antonio Sabio Pinilla y María Dolores Valencia (eds.): Seis estudios sobre la traducción en los siglos XVI y XVII, Granada: Comares, 205-242.

Garcia Peres, Domingo (1890): Catálogo biográfico y bibliográfico de los autores portugueses que escribieron en castellano, Madrid: Imprenta del Colegio Nacional de Sordo-Mudos y de Ciegos.

GIL, Lamberto (1911) [1818]: «Prólogo del traductor», en Luis de Camoens, Los Lusíadas, trad. Lamberto Gil, Madrid: Librería de Perlado, Páez y C. ${ }^{a}$.

GómEZ BAYARRI, José Vicente (2015): «La tradición cronística valenciana: Martín de Viciana», Revista digital de la Real Academia de Cultura Valenciana, 1-28, <http://www.racv.es/institucional/es/racv_ digital/seccion-historia>.

GonÇALVES Rodrigues, António Augusto (1992): A Tradução em Portugal. Tentativa de resenha cronológica das traduções impressas em língua portuguesa excluindo o Brasil de 1495 a 1950. Volume primeiro 1495-1834, Lisboa: INCM. 
GoYRI, Nicolás (1880): Estudio crítico-analitico sobre las versiones españolas de Os Lusíadas (Canto primero), Lisboa: Typographia de J. M. Verde.

LoHMAN VilLENA, Guillermo (1969): «Enrique Garcés, descubridor del mercurio en el Perú, poeta y arbitrista», Studia, Revista do Centro de Estudos Históricos Ultramarinos de Portugal, 27-28, 7-62.

Mendiguren, Xabier (2004): «El ámbito de la cultura vasca», en Francisco Lafarga y Luis Pegenaute (eds.), Historia de la traducción en España, Salamanca: Ambos Mundos, 791-815.

Micó, José María (2004): «La época del Renacimiento y Barroco», en Francisco Lafarga y Luis Pegenaute (eds.), Historia de la traducción en España, Salamanca: Ambos Mundos, 175-208.

MoreirA, Rafael (2017): «O tradutor para castelhano dos tratados de Holanda: Manuel Dinis, c. 15051565?», Studies on the Classical Tradition, 5/2, 13-25, $<$ https://novaresearch.unl.pt/en/publications/otradutor-para-castelhano-dos-tratados-de-holanda-manuel-dinis-c>.

Nogueras Valdivieso, Enrique y Lourdes Sánchez Rodrigo (1999): «Notas sobre la traducción de la poesía románica medieval: cuatro siglos de Ausiàs March», en Juan Paredes y Eva Muñoz Raya (eds.), Traducir la Edad Media. La traducción de la literatura medieval románica, Granada: Universidad de Granada, 167-206.

NoIA, Camiño (2004): «El ámbito de la cultura gallega», en Francisco Lafarga y Luis Pegenaute (eds.), Historia de la traducción en España, Salamanca: Ambos Mundos, 721-790.

PONS DE ICART, Luis, (1573): Libro de las grandezas y cosas memorables de la ciudad de Tarragona, Lérida: Juan de Villanueva y Pedro de Robles, <http://bdh-rd. bne.es/viewer.vm?id=0000115552\&page $=1>$.

Pujol, Josep (2004): «El ámbito de la cultura catalana: Traducciones y cambio cultural entre los siglos XIII y XV», en Francisco Lafarga y Luis Pegenaute (eds.), Historia de la traducción en España. Salamanca: Ambos Mundos, 623-650.

RICARD, Robert (1972): «Les traductions castillaines de l'Imagem da Vida Cristã», Bulletin Hispanique, 74/3-4, 436-443, <https://www.persee.fr/doc/hispa_0007-4640_1972_num_74_3_4085>.
Ruiz Casanova, José Francisco (2018): Ensayo de una historia de la traducción en España, Madrid: Cátedra.

Russell, Peter (1985): Traducciones y traductores en la Península Ibérica (1400-1550), Barcelona: Bellaterra.

Sabio Pinilla, José Antonio (1983): Traducciones en verso castellano de Os Lusíadas de Luis de Camoens, Granada: Universidad de Granada (memoria de licenciatura inédita).

SABio PInILla, José Antonio (1990): La crítica a Os Lusíadas en Portugal (1572-1987), Granada: Ediciones TAT.

SAbio Pinilla, José Antonio (2012): «Notas para la historia de traduzir (con mención a sus derivados y a otras expresiones)», en Juan José Lanero y José Luis Chamosa (eds.), Lengua, traducción, recepción: en honor a Julio-César Santoyo, vol. II, León: Universidad de León, 455-478.

SAbio Pinilla, José Antonio y María Manuela Fernández Sánchez (2001): «O Marco Paulo de Valentim Fernandes: uma contribuição singular para a história da tradução peninsular», Discursos, 1, 87-102, $<$ http://handle/10400.2/4094>.

SÁnchez Rodrigo, Lourdes y Enrique Nogueras Valdivieso (2000): «Ausiàs March y Jorge de Montemayor: traducción e interpretación», Annexes des Cahiers de linguistique hispanique médiévale, 14, $357-$ 374. [Ausias March (1400-1459). Premier poète en langue catalane], <http://www.persee.fr/doc/ cehm_0180-9997_2000_sup_14_1_2223>.

SAnToyo, Julio-César (2004): «El siglo XIv: Traducciones y reflexiones sobre la traducción», Livivs, 6, 1734, <http://hdl.handle.net/10612/6349>.

SAnToYo, Julio-César (2009): La traducción medieval en la Península Ibérica (siglos III-XV), León: Universidad de León.

SAntoyo, Julio-César (2010): «Autotraducciones intrapeninsulares: motivos históricos, razones actuales», en Enric Gallén, Francisco Lafarga y Luis Pegenaute (eds.), Traducción y autotraducción en las literaturas ibéricas, Berna: Peter Lang, 365-380.

Simón DíAz, José (1992): Bibliografía de la literatura hispánica, tomo xv, Madrid: Consejo Superior de Investigaciones Científicas.

VAlsalobre, Pep (2001): «De l'spill de la vida religiosa al Desitjós. Notes a una novel-la al-legòrica del segle XVI», Caplletra, 31, 11-23. 